\title{
Circulating Tumor Cell Cultures as a Predictive Marker during Salvage Therapy of Refractory Merkel Cell Carcinoma with Chemotherapy and Electron Beam Radiation
}

\author{
Sreekanth Donepudi ${ }^{1}$, Susan A. Reisinger ${ }^{2}$, John R. McGregor ${ }^{3}$, Shweta Tharkar $^{3}$, \\ Suzanne Samlowski ${ }^{3}$, Daniel Ostler ${ }^{4}$, Shirley Shen ${ }^{5}$, Wolfram E. Samlowski ${ }^{{ }^{*}}$ \\ ${ }^{1}$ Comprehensive Cancer Centers of Nevada, Las Vegas, USA; ${ }^{2} 21$ st Century Radiation Oncology, Las Vegas, USA; ${ }^{3}$ TrueCells, LLC, \\ Las Vegas, USA; ${ }^{4}$ LMC Pathology, Las Vegas, USA; ${ }^{5}$ Genomics Core Facility of UNLV, Las Vegas, USA. \\ Email: ${ }^{*}$ wolf.samlowski@usoncology.com
}

Received July $5^{\text {th }}$, 2013; revised August $3^{\text {rd }}, 2013$; accepted August $10^{\text {th }}, 2013$

Copyright (C 2013 Sreekanth Donepudi et al. This is an open access article distributed under the Creative Commons Attribution License, which permits unrestricted use, distribution, and reproduction in any medium, provided the original work is properly cited.

\begin{abstract}
Metastatic Merkel Cell carcinoma (MCC) is a highly unusual and aggressive skin cancer that presents as a small, pink to violet skin lesion and metastasizes early in its growth. Metastatic MCC is generally treated with small cell lung cancer chemotherapy regimens, because the tumor consists of neuroendocrine cells, but patients generally do not have durable responses. The pathogenesis of MCC has recently been attributed to the Merkel Cell polyoma virus. This virus activates the cellular retinoblastoma oncoprotein and cell cycle machinery, triggering continual cellular proliferation. A 77-year-old man developed extensive MCC metastases, involving more than one fourth of his scalp and numerous cervical lymph nodes. Following failure of initial chemotherapy and radiation, effective palliation was achieved by using a sequence of electron-beam radiotherapy, low dose gemcitabine, and etoposide, resulting in significant periods of tumor regression and prolonged survival. A novel circulating tumor cell (CTC) culture assay was performed on four separate clinic visits during the treatment period. Tumor colonies were cultured from the patient's peripheral blood and CTC colony counts were correlated with clinical treatment response. Not only did the patient respond to palliative cell cycle directed chemotherapy and electron beam radiation, but we demonstrated that CTC can be cultured from peripheral blood of MCC patients and serve as a predictive marker to monitor treatment response.
\end{abstract}

Keywords: Merkel Cell Carcinoma; Chemotherapy; Radiotherapy; Circulating Tumor Cells; CTC Culture

\section{Introduction}

Merkel Cell Carcinoma (MCC) is believed to originate from neuroendocrine skin cells derived from neural crest tissue [1]. When neoplastic transformation occurs, a rare but highly virulent skin cancer is resulted. The age-adjusted incidence of MCC in the United States is estimated to be 0.24 per 100,000 people per year [2]. MCC occurs most often in Caucasian men over the age of 65 [3]. Areas exposed to chronic sun exposure are the most frequent sites for MCC, especially in the head and neck region [3]. Approximately $20 \%$ of cases arise in the periorbital or eyelid area, $40 \%$ on an extremity, and $10 \%$ on the trunk [4]. Immunodeficiency and immunosuppression, including patients with chronic lymphoid malignancies,

\footnotetext{
${ }^{*}$ Corresponding author.
}

HIV, and renal transplants may also play an important role in the development of MCC [3,5-7].

Once MCC becomes metastatic, it is a highly aggressive skin cancer with a median survival of only 8 to 12 months. Patients are often treated with small cell lung cancer-type regimens as first line therapy [8]. Due to the rarity of this disease, there is a lack of consensus about treatment options after failure of first-line therapy [9]. Since most MCC patients are elderly, often suffering from other comorbid illnesses, many physicians are reluctant to use aggressive treatment options [8].

We present a case of metastatic MCC in a 77-year-old man who had remarkable responses to sequential treatments of topical electron beam radiation and cell cycle directed chemotherapy, spanning forty months. During this period, four peripheral blood samples were drawn at 
clinic visits. Circulating tumor cells were cultured from these samples using a novel technology [10]. Tumor colonies were counted and compared to the patient's clinical disease and response to treatment. We demonstrated that CTC cultures represent a potential predictive marker in patients with MCC.

\section{Report of Case}

\section{Salvage Treatment with Sequential Electron Beam Radiotherapy and Chemotherapy}

A 77-year-old Caucasian male with a history of significant coronary artery disease was diagnosed with a $0.8 \mathrm{~cm}$ MCC on the right side of his scalp. The tumor was initially treated with a wide local excision and skin graft on 10/15/09. Within two weeks an additional metastatic nodule appeared on the vertex of the scalp, and was excised. The patient was seen on 8/12/10 with several additional areas of "in-transit" scalp involvement, anterior to the original resection site. Due to medical frailty, he was treated conservatively with 3 cycles of non-cisplatin based chemotherapy, using cyclophosphamide, methotrexate, and 5-fluorouracil (CMF) [11]. Dramatic improvement in the skin lesions was observed. Electron beam radiotherapy, 66 Gy, was then administered to the anterior right scalp in 33 fractions at 2 Gy per fraction over the interval from $11 / 16 / 10$ to $1 / 7 / 11$ to prior sites of scalp recurrence (arrow) (Figure 1(a)). Three further cycles of CMF chemotherapy were administered following the completion of radiotherapy.

On 3/18/11 the patient recurred with a number of subcutaneous tumors on the contralateral scalp (Figure 1(b)). Computed tomography scans of chest, abdomen, pelvis, and brain did not identify metastatic disease. Following informed consent, a novel and experimental circulating tumor cell (CTC) culture assay was performed using 10 $\mathrm{ml}$ of peripheral patient blood (Table 1; CTC sample 001a). More than 500 CTC colonies grew in 8 replicate 60 -mm petri dishes. A typical MCC colony from this CTC culture is shown (Figure 2(a)). The patient was subsequently enrolled in a clinical trial of CD56 maytansine-linked toxin monoclonal antibody (BB-0019). Following the first dose of BB-0019 he developed unstable angina. Treatment with BB-0019 was halted and the patient was withdrawn from this trial. He was subsequently treated with four courses of carboplatin and etoposide, and achieved a transient response of his scalp lesions.

In September of 2011, our patient developed a $4 \mathrm{~cm}$ left eyelid mass and underwent a palliative resection. There was a simultaneous progression of disease on the left scalp, posterior scalp, and right side of the neck (Figure 1(c)). A second CTC assay was performed, again using $10 \mathrm{ml}$ of the patient's blood (Table 1; 001b). Electron beam radiation was again administered to the af-
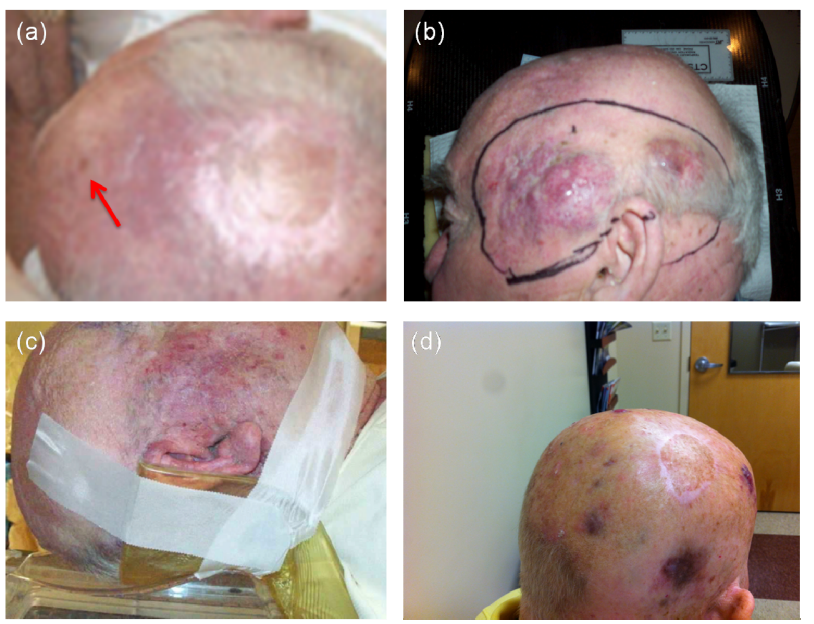

Figure 1. Clinical photographs of MCC scalp metastases during treatment. (a) Site of radiotherapy to original small in-transit metastases anterior to primary tumor resection site on right anterior scalp (arrow), 8/12/10; (b) Large area of contralateral scalp tumor recurrence 9/21/11. Lines indicate planned electron beam treatment; (c) Recurrent tumor right cheek and posterior neck 10/7/11; (d) Dramatic clinical response following electron beam RT plus low dose i.v. gemcitabine every other week, 3/7/12.
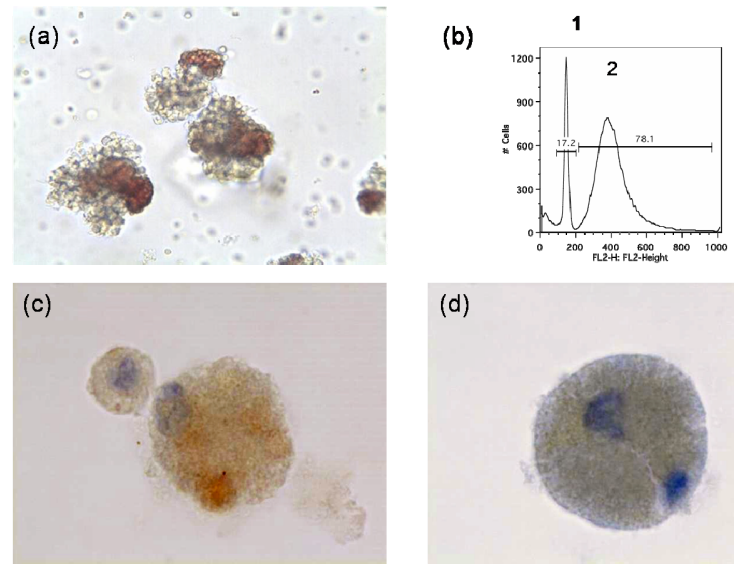

(d)

Figure 2. Characterization of MCC CTC colonies. (a) MCC tumor colonies grown in TrueCells culture medium for 16 days (001a; 20× magnification); (b) Flow cytometric identification of host cells (1: narrow diploid host cell histogram peak) and MCC tumor cells (2: broad aneuploid tumor cell peak) from enzymatically dissociated MCC CTC colonies following propidium iodide staining; (c) Immunostaining of dissociated CTC tumor cells for cytokeratin-20; (d) Immunostaining of dissociated CTC tumor cells for synaptophysin.

fected areas (total dose of $44 \mathrm{~Gy}$ in 22 fractions at $2 \mathrm{~Gy}$ per fraction) from $9 / 21 / 11$ to $11 / 13 / 11$. The tumor initially responded to radiotherapy in these areas, but some new areas of tumor progression were noted. Gemcitabine was added at attenuated doses $\left(800 \mathrm{mg} / \mathrm{m}^{2}\right.$ every other week from $11 / 8 / 11$ to $2 / 1 / 12$ ) with additional electron beam radiotherapy to include all affected areas of the 
Table 1. Culture of Merkel cell CTC from sequential patient blood samples.

\begin{tabular}{cccccc}
\hline Sample & Date & $\begin{array}{c}\text { Input } \\
\text { (WBC) }\end{array}$ & $\begin{array}{c}\text { Colonies } \\
\text { (No.) }\end{array}$ & $\begin{array}{c}\text { Cell } \\
\text { recovery }\end{array}$ & ALDH + (\%) \\
\hline 001a & $3 / 28 / 11$ & $4.60 \times 10^{6}$ & $>500$ & ND & ND \\
$001 \mathrm{~b}$ & $2 / 15 / 12$ & $3.70 \times 10^{6}$ & $202 \pm 14$ & 300,000 & $2.0 \pm 0.3$ \\
$001 \mathrm{c}$ & $5 / 31 / 12$ & $5.1 \times 10^{6}$ & $17 \pm 1.5$ & 140,000 & $1.3 \pm 0.4$ \\
$001 \mathrm{~d}$ & $9 / 24 / 12$ & $5.5 \times 10^{6}$ & $31 \pm 1.5$ & 940,000 & $0.9 \pm 0.1$ \\
+ & & $10^{6}$ & $11 \pm 6$ & $\mathrm{ND}$ & $95.9 \pm 1.6$ \\
- & & $10^{8}$ & $0.3 \pm 0.7$ & $\sim 9 \times 10^{6}$ & $0 \pm 0$ \\
\hline
\end{tabular}

$\mathrm{ND}=$ not done. Patient blood was drawn into acid citrate dextrose (ACD) anticoagulant containing vacutainer tubes $(10 \mathrm{ml})$. Peripheral blood leukocytes (WBC) were isolated using Ficoll-Hypaque centrifugation and cultured in TrueCells medium for 16 days. Cell colonies were counted (sum of 8 replicate $60 \mathrm{~mm}$ plates \pm standard deviation). Colonies were isolated using a micropipette and dissociated in Accutase. Following fixation and permeabilization in BD Cytofix/Cytoperm, cells were stained for ALDH expression (a putative stem cell marker). The percentage of stained cells is shown. M14 melanoma cells (+control) served to establish the frequency of colonies that could be expected from a melanoma cell line. Buffy coat leukocytes from normal individuals (-control) did not grow significant numbers of colonies in this assay.

scalp (45 Gy in 25 fractions from 2/8/12 to 3/7/12 at reduced dose of 1.8 Gy per fraction due to prior treatment), including some overlap of the previously treated radiation fields. This resulted in a dramatic treatment response (Figure 1(d)). A third CTC assay was performed during a routine clinic visit during this period (Table 1; 001c).

On February 15, 2012, additional tumor progression to new areas of the patient's scalp was treated with single agent etoposide ( $50 \mathrm{mg} / \mathrm{m}^{2}$, i.v. twice weekly). This resulted in another almost complete tumor regression.

Another CTC assay was performed (Table 1; 001d). CTC colonies from this sample were dissociated and tumor cells were identified by flow cytometry as being aneuploid (Figure 2(b)), and by staining with mAb directed against cytokeratin 20 (Figure 2(c)) and synaptophysin (Figure 2(d)).

Despite repeated relapses in the scalp and the presence of CTC colonies in the peripheral blood, no distant metastases were seen on CT scans of chest, abdomen, pelvis, or brain.

Subsequently the patient developed a more rapid downhill course. In part, this was a consequence of increasing toxicity from more aggressive chemotherapy regimens, including episodes of febrile neutropenia and diarrhea. He also developed shortness of breath and hypoxia representing lymphangitic tumor involvement in the lungs. The last CTC sample 001d presaged this disease progression. Unfortunately he was not seen in clinic again during this period and no further CTC samples were obtained. He had survived 40.2 months from the start of chemotherapy, well beyond the average for metastatic MCC. The patient finally died in hospice in July of 2012.
Ideally, a final blood sample should have been obtained and final CTC assay performed, but was not possible because the patient was constantly in the hospital. Our subsequent experience suggests that the number of CTC colonies near the end of his life would have been large, as the MCC had become resistant to treatment. We believe that the CTC culture assay acted as an "intermediate marker" in this patient. It corresponded closely with treatment responses, and suggested tumor progression (see increase in colony count sample MCC-001d), prior to catastrophic treatment failure.

\section{Materials and Methods}

Following signed acknowledgement of informed consent from the patient to participate in the IRB approved protocol; $10 \mathrm{ml}$ of anticoagulated blood was drawn on four occasions. This study is registered in the NCI database (http://www.clinicaltrials.gov/show/NCT01528774). CTC samples were sent to TrueCells, LLC, Las Vegas, NV, for processing.

The buffy coat (white blood cell fraction, containing CTC) from $10 \mathrm{ml}$ vacutainer tubes was separated by Ficoll/Hypaque centrifugation, and split into 8 replicate cultures in proprietary True Cells medium (patent pending). After 16 days in culture, tumor colonies were counted.

CTC colonies were then harvested individually using a sterile micropipette and dissociated using Accutase. Following extensive washes, cells were fixed in BD Cytofix/Cytoperm (Becton Dickinson, Franklin Lakes, NJ) and stained with propidium iodide $(50 \mu \mathrm{g} / \mathrm{ml})$. Cells were analyzed by flow cytometry. Using forward and side scatter, samples were gated to identify a single cell population. This population was analyzed for DNA content by using a Becton Dickinson FACS Calibur (BD Biosciences, San Jose, CA) and data was subsequently analyzed using Flow-Jo software (TreeStar, Inc.). Cells were also used to prepare slides for immunohistochemical staining.

These slides were stained with anti-synaptophysin (MRQ-40) and cytokeratin 20 (SP-73) rabbit anti human mAb (Ventana Medical Systems, Tucson, AZ) using a BenchMark Ultra Staining system with the Optiview DAB hapten-detection system (Ventana).The slides were then counterstained with hematoxylin prior to evaluation.

Parallel slides were stained with a non-specific primary antibody together with the secondary detection reagent to serve as a specificity control.

\section{Discussion}

MCC is a rare, but highly aggressive skin cancer that appears to be steadily increasing in incidence in the United States. A novel polyoma virus has been identified 
as a likely causative agent for MCC. This is carried on the skin of most normal individuals of all races. Its DNA becomes clonally integrated into the tumor in patients who develop MCC $[12,13]$. The Merkel Cell virus (MCV) encodes two major families of genes: (1) the early-tumor associated large $\mathrm{T}$ antigen (LT) and small $\mathrm{T}$ antigen (ST), and (2) the late genes (viral proteins [VP]) [12]. The LT is characteristically truncated in MCC tumors. This aberrant protein can be detected in the nuclei of tumor cells in over $90 \%$ of MCC patients. The LT truncation does not appear to affect Rb binding $[14,15]$. However, the LT truncation prevents further viral replication, but activates continual abnormal tumor cell growth [12]. Like other polyoma viruses, it is believed that MCC LT/Rb interaction promotes cyclin dependent kinase activation and induces the transition of cells from $\mathrm{G}$ to $\mathrm{S}$ phase $[14,16]$.

This new understanding of the pathogenesis of MCC made us hypothesize that traditional cell cycle specific chemotherapy agents, such as nucleoside analogues, would be useful as palliative therapy by interfering with LT-driven cell cycle progression. Our patient responded well to this treatment approach, using sequential low dose gemcitabine and etoposide therapy. It may be useful to specifically test these and other cell cycle specific chemotherapy agents in future MCC chemotherapy protocols. Since MCC cells are continually dividing, these tumors have long been known to be quite radiosensitive, providing another useful treatment modality $[17,18]$.

Researchers believe that detection of tiny numbers (perhaps 1-100 in $10 \mathrm{ml}$ blood) of CTC in the blood of cancer patients provides prognostic and predictive information related to survival $[19,20]$. These CTC are thought to be in the process of creating new metastases. TrueCells has developed a rapid, efficient, and inexpensive strategy for CTC recovery in a high percentage of metastatic cancer patients. This technology allows viable CTC to be isolated, cultured, and expanded, providing suitable numbers of cancer cells for subsequent genetic or molecular analysis within 3 weeks of blood sampling. An advantage of this approach is that all tumor cells contained within the white blood cell fraction of blood are potentially able to grow. There is no need for antibodybased selection and no growth factors are added to the medium to bias selection of cells. Using this technology, we have been able to cultivate substantial numbers of CTC colonies from a wide variety of metastatic cancer patients, including breast, lung, prostate, melanoma, sarcoma, renal cancer, and pancreas. We believe that this is to be the first report of successful isolation and culture of MCC CTC as a predictive marker for treatment outcome. CTC colony counts appeared to show a steady decrease while the patient was responding, but change in this trend and the rise in colony counts in the last set of CTC cultures (001d) presaged the imminent treatment failure.

\section{Acknowledgements}

We would like to thank the clinical nursing staff, pharmacy, and clinical trials office at the Southern Hills office of Comprehensive Cancer Centers of Nevada for obtaining the CTC samples for analysis and providing excellent patient care.

The Genomics Core Facility of UNLV is supported by grants from the National Center for Research Resources (5P20RR016464-11) and the National Institute of General Medical Sciences (8P20GM103440-11).

We would also like to thank our patient and his family for participating in the CTC study and providing blood samples.

\section{REFERENCES}

[1] A. Van Keymeulen, G. Mascre, K. K. Youseff, I. Harel, C. Michaux, N. De Geest, C. Szpalski, Y. Achouri, W. Bloch, B. A. Hassan and C. Blanpain, "Epidermal Progenitors Give Rise to Merkel Cells during Embryonic Development and Adult Homeostasis,” Journal of Cell Biology, Vol. 187, No. 1, 2009, pp. 91-100. doi:10.1083/jcb.200907080

[2] N. Vilar-Coromina, F. Perez Bueno, M. Alsina Maqueda, L. Vilardell Gil, A. Izquierdo Font and R. Marcos-Gragera, "Merkel Cell Cancer of the Skin: Population-Based Incidence and Survival, 1995-2005,” Medicina Clínica, Vol. 132, No. 18, 2009, pp. 701-703.

doi:10.1016/j.medcli.2008.10.056

[3] R. W. Miller and C. S. Rabkin, "Merkel Cell Carcinoma and Melanoma: Etiological Similarities and Differences,” Cancer Epidemiology, Biomarkers \& Prevention, Vol. 8, No. 2, 1999, pp. 153-158.

[4] M. Agelli and L. X. Clegg, "Epidemiology of Primary Merkel Cell Carcinoma in the United States," Journal of the American Academy of Dermatology, Vol. 49, No. 5, 2003, pp. 832-841. doi:10.1016/S0190-9622(03)02108-X

[5] E. Lanoy, G. M. Dores, M. M. Madeleine, J. R. Toro, J. F. Fraumeni and E. A. Engels, "Epidemiology of Non-Keratinocytic Skin Cancers among Persons with AIDS in the United States," Infectious Agents and Cancer, Vol. 23, Suppl 2, 2009, pp. 385-393.

[6] V. Koljonen, H. Kukko, E. Tukiainen, T. Bohling, R. Sankila, E. Pukkala, H. Sihto, H. Joensuu, L. Kyllonen and H. Makisalo, "Incidence of Merkel Cell Carcinoma in Renal Transplant Recipients,” Nephrology Dialysis Transplantation, Vol. 24, No. 10, 2009, pp. 3231-3235. doi:10.1093/ndt/gfp334

[7] M. Heath, N. Jaimes, B. Lemos, A. Mostaghimi, L. C. Wang, P. F. Penas and P. Nghiem, "Clinical Characteristics of Merkel Cell Carcinoma at Diagnosis in $195 \mathrm{~Pa}-$ tients: The AEIOU Features," Journal of the American Academy of Dermatology, Vol. 58, No. 3, 2008, pp. 375381. doi:10.1016/j.jaad.2007.11.020

[8] S. Donepudi, R. C. Deconti and W. E. Samlowski, "Recent Advances in the Understanding of the Genetics, Eti- 
ology and Treatment of Merkel Cell Carcinoma," Seminars in Oncology, Vol. 39, No. 2, 2012, pp. 163-172. doi:10.1053/j.seminoncol.2012.01.003

[9] P. J. Allen, W. B. Bowne, D. P. Jaques, M. F. Brennan, K. Busam and D. G. Coit, "Merkel Cell Carcinoma: Prognosis and Treatment of Patients from a Single Institution," Journal of Clinical Oncology, Vol. 23, No. 10, 2005, pp. 2300-2309. doi:10.1200/JCO.2005.02.329

[10] W. E. Samlowski, J. R. McGregor, S. Tharkar, S. Donepudi and S. Ferrone, "Isolation and Expansion of Circulating Tumor Cells (CTC) from Melanoma Patients Using a Novel Cell Culture Technique,” Journal of Clinical Oncology, Vol. 30, 2012, Article ID: abstr 10614.

[11] E. Fenig, H. Lurie and A. Sulkes, "The Use of Cyclophosphamide, Methotrexate and 5-Fluorouracil in the Treatment of Merkel Cell Carcinoma," American Journal of Clinical Oncology, Vol. 16, No. 1, 1993, pp. 54-57. doi:10.1097/00000421-199302000-00014

[12] H. Feng, M. Shuda, Y. Chang and P. S. Moore, "Clonal Integration of a Polyomavirus in Human Merkel Cell Carcinoma,” Science, Vol. 319, No. 5866, 2008, pp. 10961100. doi:10.1126/science. 1152586

[13] J. C. Becker, R. Houben, S. Ugurel, U. Trefzer, C. Pfohler and D. Schrama, "MC Polyomavirus Is Frequently Present in Merkel Cell Carcinoma of European Patients," Journal of Investigative Dermatology, 2008, p. 198.

[14] R. Houben, M. Shuda, R. Weinkam, D. Schrama, H. Feng, Y. Chang, P. S. Moore and J. C. Becker, "Merkel Cell Polyomavirus-Infected Merkel Cell Carcinoma Cells Require Expression of Viral T Antigens," Journal of Virology, Vol. 84, No. 14, 2010, pp. 7064-7072. doi:10.1128/JVI.02400-09
[15] M. Shuda, H. Feng, H. J. Kwun, S. T. Rosen, O. Gjoerup, P. S. Moore and Y. Chang, "T Antigen Mutations Are a Human Tumor-Specific Signature for Merkel Cell Polyomavirus," Proceedings of the National Academy of Sciences of the United States of America, Vol. 105, No. 42, 2008, pp. 16272-16277. doi:10.1073/pnas.0806526105

[16] R. Arora, Y. Chang and P. S. Moore, "MCV and Merkel Cell Carcinoma: A Molecular Success Story,” Current Opinion in Virology, Vol. 2, No. 4, 2012, pp. 489-498. doi:10.1016/j.coviro.2012.05.007

[17] L. C. Fang, B. Lemos, J. Douglas, J. Iyer and P. Nghiem, "Radiation Monotherapy as Regional Treatment for Lymph Node-Positive Merkel Cell Carcinoma,” Cancer, Vol. 116, No. 7, 2010, pp. 1783-1790. doi:10.1002/cncr.24919

[18] L. Khan and E. A. Barnes, "Radiotherapy for Metastatic Merkel Cell Carcinoma: A Review of the Literature," Journal of Skin Cancer, Vol. 2012, 2012, Article ID: 654981. doi:10.1155/2012/654981

[19] D. R. Parkinson, N. Dracopoli, B. G. Petty, C. Compton, M. Cristofanilli, A. Deisseroth, D. F. Hayes, G. Kapke, P. Kumar, J. Lee, M. C. Liu, R. McCormack, S. Mikulski, L. Nagahara, K. Pantel, S. Pearson-White, E. A. Punnoose, L. T. Roadcap, A. E. Schade, H. I. Scher, C. C. Sigman and G. J. Kelloff, "Considerations in the Development of Circulating Tumor Cell Technology for Clinical Use," Journal of Translational Medicine, Vol. 10, 2012, p. 138. doi:10.1186/1479-5876-10-138

[20] B. Faltas, "Cornering Metastases: Therapeutic Targeting of Circulating Tumor Cells and Stem Cells," Frontiers in Oncology, Vol. 2, 2012, p. 68. doi:10.3389/fonc.2012.00068 